\title{
Exploration of Image-building and Cultural Dissemination in Films and Television Drama from the Perspective of Regional Culture
}

\author{
Luo Xin \\ Xi'an Fanyi University, Xi'an, Shaanxi710105, China \\ 40963339@qq.com
}

Keywords:Regional culture; Film and television art; Image-building; Cultural dissemination

\begin{abstract}
Huge cultural differences among different countries and nations have long been existing in the world and various regional cultures provide a great deal of materials and inspirations for all kinds of artistic creation. Meanwhile, many works of art such as painting, music, film and television also help spread and pass on culture. Due to the interaction between regional culture and film and television art, research on the creation of film and television art from different geographical perspective will play a positive role in boosting cultural dissemination and in understanding and building artistic images. This paper strives to illustrate the artistic image-building and cultural dissemination in different areas through analyzing the natural landscape, the portrayal of characters, the application of localized language and the inheritance of special skills showed in films and television drama in hopes of comprehending the two - way interaction between regional culture and film and television art.

The most important reason for the development of film and TV art lies in the progress of technology and the innovation in conception. The former depends on science and technology, while the latter on the inheritance and shaping of culture, which offers continuous material and inspirationfor the creation of film and TV art both in time and space. Regional diversity results from the diversification of film and television art. Combining sound, picture and certain plots and providing both audio-visual enjoyments, film and television art shows different geographical, ethnic and other local elements to the audience. The following parts will give detailed exposition and examples of the image-building and culture dissemination in films and television drama of different regions.
\end{abstract}

\section{The Localization of Image-building and Cultural Dissemination in Films and Television Drama}

It is said that "the unique features of a local environment always give special characteristics to its inhabitants”. Distinctive geographical characteristics have made film and television art in diversity. In order to make the film and television art full of vitality andfulfill the role of spreading culture, creators and photographers always try to find the most suitable place to achieve the aesthetic objectification. Regional culture is a combination of human and nature, and all the activities of human civilization are naturally geographical orientated, hence creating the Han culture, the San -Qin(Shaanxi) culture, Ba-Shu(Sichuan) culture,ect.. Generally speaking, the display of landscape and the molding of images have become the best carrier for spreading the film and television art culture. In the following, the paper will elaborate on the display and spread of regional culture from the aspects of the display of natural landscape, the portrayal of the characters, the application of the 
local language and the inheritance of special skills.

\section{Display of the natural landscape}

Films and television drama are forms of art which feature narrating through space modeling. Therefore, film and television art focusing on regional characteristics is bound to be closely related with the geographical environment, and sometimes the external natural landscape is a strong symbol of regional spirit. Usually in films and television drama, the choice of sites, the contrasting of atmosphere and even the setting of furnishings are necessary prerequisites for cultural transmission. Influenced by social, economic, cultural, political and other factors, a certain region is given more humanistic properties. So many film and television creators spare no effort to use natural landscapes to lay the emotional tone of the story, frequently used natural landscapes such as the ancient city of Beijing, luxurious anddissipated Shanghai, tender and delicate southern cities, and wild and bleak deserts, etc.. People's the living conditions and customs are more or less reflected form certain landscapes. A representative of this kind in Chinese film and television industry is known as the "Chinese Western Films" including “Old Well”, "Yellow Earth” and "Red Sorghum” which show the unique culture of the Western regions through the display of western natural scenery. The endless loess slopes in those films mean life's poverty and desperation, but audience are also impressed by local people's toughness and unremitting tenacity which are deeply rooted in the soil of Chinese culture.

\section{Character image-building}

Hippolyte Adolphe Taine, a well-known French literary theorist and historian, has pointed out that material culture and spiritual culture depend on races, environment and times, which indicates the interaction between people and local culture. As the direct carrier of civilization and spirit, character image-building in film and television art has become a primary element in displaying regional culture. Characters are molded into two aspects: external and internal. The external image will give the audience a strong visual impact, and help form the audience's first impression towards the character such as beautiful or ugly; simple or snobbish. As in the movie "Yellow Earth", the character-the heroine Cuiqiao's father, a peasant in Northern Shaanxi province is a success. His image reminds audience a famous oil painting “Father" by Luo Zhongli. In the weak light, he who at his fifty is molded like a clay sculpture, a withered and thin face covered with gully-like wrinkles. His deep-set eyes reveal kindness and simplicity, as well as sadness and confusion, a typical image of an old peasant in northern Shaanxi which wins people's sympathy.

The building of the external images of characters is far from enough to express the core of art. In order to further the exhibition of regional culture, it is necessary to explore something deep rooted in the formation of the character's disposition, usually through the words and deeds of the characters. In film and television art, it is often seen from words and deeds stimulated by various contradictions in life. In other words, the narration and design of the story should highlight the character's disposition. An outstanding example of image-building is the hero in the movie " $M r$. Six" starred by Feng Xiaogang. The film tells the story of a 50-or-so-year-old street punk called "Mr. Six" who has reigned over the Beijing streets as the neighborhood kingpin for many years.Heattempts to settle the debts of his son by relying on his old school rules. From the hero Mr. Six, we see a unique secular Chinese belief. When Mr. Six, the man of few words said: "although we are small potatoes, we have to make things settled", audience were touched because they regarded him as one of them. The building of the character Mr. Six is also reflected in many details 
in the film, such as when Mr. Six saw a man disguised as a blind man to beg, he didn't expose him, but amused him; when he caught a thief, he educated him and let him go and then he mailedall the documents and money back to the victim. All those details build an image of an authentic Beijinger. In short, the director of the film Guan Hu, through the molding of the hero Mr. Six, portrays a city, an era, a group of people under great changes, and the elapsing of regional culture,which is thought-provoking.

\section{The application of local language}

Language is one of the important media for carrying culture, and language not only reflects the feelings and thoughts of people, but also maintains the history and wisdom of different regions. Different cultures give different characteristics to languages, and the regional cultures created by languages are constantly being inherited and extolled. The language has become a typical symbol of a regional cultural. In film and television art, the application of the local language and dialect is an effective means to show regional culture, even in fragments. Sometimes the unfamiliarity of the dialect can achieve a kind of humor and make people laugh. As in the movie "Crazy Stone", a number of different dialects appear and mix together, thus making the film full of local flavor and funny, which not only creates the typical characters, but also shows characteristics and local customs of different regions.

With the change of the times and the change of the human's aesthetic, national culture has been paid more and more attention. The application of local languages and dialects in the film and TV art also transmits from grass root culture to cultural identity. The famous critic Ma Ke in his "Dialect film: cultural consciousness and revival" points out that the early application of local dialectswas expected to create a humorous atmosphere, but now, the role of dialect is quite different. It is more of a direct display of local culture and identity. From the artistic aspect, dialect, as a living feature of regional culture, is something that can be heard and perceived by audience. It is more impressive than words and descriptions. When language and culture are well collaborated, then the works of art will contain more aesthetic meaning and leave people deep impression. The director Hao Jie, born in 1980s, has made many attempts in his films "Single Man”, “The Love Songs of Tie Dan”, "My Original Dream". In those films, dialects are in complete application. All the characters speak in Changchiakou dialect, and tell the audience directly where the story happened, displaying the region's life and cultural background. Local audience have sympathetic response, while other audience can have a better understanding of Hebei culture and the local people's ideology, life style, which is the source of their helplessness and poverty .

\section{The transmission of special skills}

Different regions have their own cultures, including a variety of non-material cultures. A particular form of art or skill is always associated with certain regional culture. For example, when shadow puppet is mentioned, we naturally think of Shaanxi and "Face Changing” usually reminds people of Sichuan opera. In films and television drama, the exhibition of special skills has also become a major manifestation of regional culture. An example is the northeast song-and-dance duet highlighted in "Liu Laogen" and "Ma Dashuai” starring by Zhao Benshan. Song-and-dance duet is famous for its simple and primitive performing, bold and popular language and humorous and witty style, which is the portrayal of Northeast people's character. Song-and-dance duet has attracted a large number of audiences in northern China not only by its special skill but also by its cultural connotation and artistic charm. So in Northeastern China, a saying goes like "We'd rather give up 
our three meals than our song and dance duets.”

Another representative of this kind is the film "Song of the Phoenix" directed by Wu Tianming, a leading figure in China's "fourth generation of directors". The film is about how Jiao Sanye and You Tianming, the new and old generations Suona artists, transmit and promote the traditional skills of the suona in a remote town named Wushuang. In the movie, the folk art suona is not played just for entertainment. Performing suona in a funeral also represents people's evaluation of the dead. However, as time changes and biased by the society, the traditional art has become a tool for begging and few people show their interest in it. Like "Life", "Old Well" and "The King of Masks", the movie adheres to realismwhich appears in many Chinese films. Facing all sorts of historical nihilism and the "westernization" tendency, traditional skills still keep the cultural awareness and cultural endurance, which endows the film with a typical regional feature.

\section{Conclusion}

Regional culture is an important source of artistic creation. It influences the creators and viewers' ideology to a great extent. Therefore, the creators of films and TV drama cannot ignore the influence of specific geographical culture in the selection of subject matter and the shaping of image and ultimately make their film and television works full of cultural precipitation and geographical attributes. Each era is accompanied by a specific history and culture, which exerts great impact on people's character and psychology. In today's society, with the rapid development of the Internet and other technologies and impacted by a great variety of cultural thoughts from different countries, a large number of modern films and television drama more or less reflect the crises in people's minds, reveal people's distorted and alienated spiritual world that lingersbetween rationalism and irrationalism, and show the humanistic thought under specific circumstances. This correspondingly provides modern film and television art with unique social significance and knowledge of values. In film and television art, either the display of the natural landscape, character image-building, or the application of local language, the transmission of special skills are all designed to convey culture and promote spirit. Therefore, there is always a two-way interactive relationship between regional culture and film and television art that cannot be overlooked.

\section{Acknowledgment}

This paper is the research result of the Scientific Research Project Supported by Education Department of Shaanxi Provincial Government: The choice of communication path of Shaanxi TV brand and the shaping of regional culture (15JK2038); and of the Art Project of Shaanxi Provincial Social Science Fund: Research on the dissemination path and strategy of local elements in Shaanxi film and television works. (2015SY055)

\section{References}

[1] He Jing, Hu Qing. Film Narration from the Perspective of Jiangxi Culture - Research on the Creation of Jiangxi Local Movies and TV Drama [J]. Youth Literator, 2013 (13): 48-49.

[2] Wu Yuxia. Analysis of the Regional Performance of Film Art [J]. Movie Literature, 2014 (19): 4-5.

[3] Zhu Jie. Modernist Film Aesthetics and Regional Culture [J]. Jin Tian, 2013 (8).

[4] Liu Fuquan, Wang Xinling. Yan Zhao Culture and Film and Television Art of Hebei Theme [J]. Great Wall, 2012 (8): 191-192. 
[5] Shi Xusheng. From Geography to Field: The Modern Transformation of Artistic Culture [J].

Modern Communication: Journal of Communication University of China, 2012, 34 (2): 73-77.

[6] Liu Changyu. A Study of Sichuan and Chongqing Dialect Film and Television Drama Creation[J]. Hubei Institute for Nationalities, 2014. 